\title{
INCONSTITUCIONALIDAD DEL ARTÍCULO 206 DEL CÓDIGO CIVIL
}

\author{
Unconstitutionality of Article 206 of the Civil Code
}

Cristina Fátima Saffie Kattan *

\begin{abstract}
Resumen: El propósito de este trabajo es presentar algunos problemas constitucionales que se plantean con la promulgación de la ley número 19.585, en concreto los relativos al artículo 206 del Código Civil. De acuerdo con esto, en primer lugar, se mostrará la evolución de la jurisprudencia y, a continuación, se tratará el tema en el ámbito de la doctrina jurídica. Los principales temas en discusión son los siguientes principios: el significado del derecho a la identidad, el reconocimiento de la igualdad total de hijos nacidos dentro o fuera del matrimonio, la importancia del interés superior del niño y el papel del artículo 206, ya mencionado. El autor afirma que el pronunciamiento de inconstitucionalidad del artículo 206 no traería ningún conflicto con los derechos de herencia de los herederos, si ha transcurrido el plazo de prescripción. Este estudio concluye que el artículo 206 del Código Civil no debe ser aplicado en ningún caso.
\end{abstract}

Palabras claves: Reclamación filiación post mortem - artículo 206 Código Civil.

Abstract: This paper aims to present some constitutional problems arising from the passage of Law 19.585, specifically problems concerning Article 206 of the Civil Code. Accordingly, the author describes the case law evolution and then tackles the relevant legal doctrine. The main issues under discussion are the following principles: the meaning of the right to identity; the recognition of the total equality of children born in- and outside of wedlock; the importance of the child's best interest principle and the role of the aforementioned Article 206. The author claims that if the statute of limitations of claiming inheritance rights has expired, proclaiming the unconstitutionality of Article 206 shouldn't generate conflicts regarding inheritance rights of the heirs. Thus, this study concludes that Article 206 of the Civil Code should not be applied under any circumstances.

Keywords: Claims of post mortem filiation - Civil Code's norm 206.

\section{Introducción}

Supongamos que a los 28 años nos enteramos que nuestro padre, de quien no teníamos noticia alguna, ha fallecido, ¿podríamos interponer una acción de reclamación de paternidad contra su sucesión para así tener derechos hereditarios? O si luego de la muerte de nuestro padre, nos damos cuenta de que nunca fuimos

\footnotetext{
*Abogada. Licenciada en ciencias jurídicas y sociales. Correo electrónico: cristinasaffie@gmail.com
}

Este artículo fue recibido el 9 de agosto de 2013, siendo aprobada su publicación con fecha 3 de septiembre de 2013. 
Saffie - Inconstitucionalidad del artículo 206 del Código Civil

reconocidos legalmente por él, y que él llevaba una doble vida con otra familia legalmente constituida, ¿quiere decir eso que nunca fuimos ni seremos su hija?

La publicación y promulgación de la Ley $\mathrm{N}^{\circ} 19.585$ transformó profundamente el sistema chileno de filiación, especialmente sus principios inspiradores, entre los que cabe destacar el de identidad, el de la igualdad y el de dar prioridad al interés superior del niño.

El segundo párrafo del Título VIII del Libro I del Código Civil trata la acción de reclamación, que permite el establecimiento formal de la filiación. Teniendo en vista solo los artículos 195, 206 y 317 de dicho cuerpo legal; ${ }^{1}$ se constata que hay distintas formas de responder estas preguntas. Es más, “(...) surge una evidente contradicción entre los artículos 206 y 317 ambos del Código Civil, ya que el primero limita los casos en que la acción de reclamación caduca por la muerte de los padres y el segundo abre la posibilidad de deducirla en cualquier tiempo". 2

\section{Evolución jurisprudencial}

Desde la entrada en vigencia de la Ley $\mathrm{N}^{\circ} 19.585$ han cambiado paulatinamente las respuestas jurisprudenciales a este asunto. En las primeras sentencias ${ }^{3}$ se niega la posibilidad de entablar la acción de reclamación contra la sucesión de un supuesto padre o una supuesta madre difunta, negándole así posibles derechos hereditarios al actor. En términos generales, esta tesis, que llamaremos restrictiva, avala la imposibilidad de transmitir la legitimidad pasiva, como regla general; admitiendo solo en ciertos casos excepciones; es decir, la acción de reclamación se

\footnotetext{
${ }^{1}$ Artículo 195 del Código Civil: "La ley posibilita la investigación de la paternidad o maternidad, en la forma y con los medios previstos en los artículos que siguen.

El derecho a reclamar la filiación es imprescriptible e irrenunciable. Sin embargo, sus efectos patrimoniales quedan sometidos a las reglas generales de prescripción y renuncia".

Artículo 206 del Código Civil: "Si el hijo es póstumo, o si alguno de los padres fallece dentro de los ciento ochenta días siguientes al parto, la acción podrá dirigirse en contra de los herederos del padre o de la madre fallecidos, dentro del plazo de tres años, contados desde su muerte o, si el hijo es incapaz, desde que este haya alcanzado la plena capacidad”. Artículo 317 del Código Civil: "Legítimos contradictores en la cuestión de paternidad es el padre contra el hijo, o el hijo contra el padre, y en la cuestión de maternidad el hijo contra la madre, o la madre contra el hijo.

Son también legítimos contradictores los herederos del padre o madre fallecidos en contra de quienes el hijo podrá dirigir o continuar la acción y, también, los herederos del hijo fallecido cuando éstos se hagan cargo de la acción iniciada por aquel o decidan entablarla".

2 RODRÍGuEZ (2010), p. 119.

3 C. Copiapó, 18 julio 2001. Rol N 7527- 2001; Tercer Juzgado de Letras de Osorno, 20 diciembre 2002. Rol No 26.172-d; Segundo Juzgado de Letras de Melipilla, 13 octubre 2004. Rol $\mathrm{N}^{\circ}$ 15.624; C. Suprema, 2 noviembre 2004. Rol N²820-2003; C. San Miguel, 7 abril 2005. Rol No 1560-2004; C. Concepción, 4 noviembre 2004. Rol N 1806-2004; Juzgado de Familia de Valdivia, 25 enero 2007. Rol No C-1505-2006; Tribunal Familia Rancagua, 31 marzo 2009. Rol 2994-2008; C. Rancagua, 8 junio 2009, Rol No 142-2009.
} 
extingue con la muerte del supuesto padre o supuesta madre, salvo en los casos del artículo 206 del Código Civil, en el cual la acción se extingue luego del plazo, que señala dicho artículo, sea por prescripción o por caducidad.

Luego de unos años se resuelve la cuestión sobre la legitimación pasiva de los herederos en la sentencia definitiva, gracias a los argumentos del famoso voto de minoría de la sentencia de la Corte Suprema de fecha $2 / 11 / 2004^{4}$ y a la promulgación de la Ley $\mathrm{N}^{\circ}$ 20.030, que permitió una mayor posibilidad de investigación del vínculo de filiación y dar curso a más demandas.

En los fallos recientes ${ }^{5}$ se pueden apreciar claramente los argumentos que admiten la legitimidad pasiva de los herederos de un supuesto progenitor difunto. En este sentido, el artículo 317 del Código Civil representa la regla general; permitiendo que sean legítimos contradictores en las acciones de reclamación los herederos del padre o madre fallecidos. Se apoya la imprescriptibilidad del derecho a reclamar la filiación; sin olvidar que sus efectos patrimoniales quedan sometidos a las reglas generales de prescripción y renuncia. La excepcionalidad del artículo 206 del Código Civil radica en que en dichos supuestos habría plazo para entablar la acción de reclamación, luego que la legitimación pasiva ha sido transmitida. Además, los principios inspiradores de la Ley $\mathrm{N}^{\circ} 19.585$ dan luces en la solución de este problema, cuestión que será tratada en un par de párrafos. Así, estas sentencias le reconocen consecuencialmente derechos hereditarios a quien entabla con éxito la acción de reclamación, siguiendo la tesis que llamaremos amplia.

\section{Fundamento del problema}

¿Cuál es la razón por la que se produce esta discusión? ¿Hay un silencio de ley, que niega la acción? ¿Existe un vacío legal? ¿Es una antinomia legal entre los artículos del Código Civil? ¿Se transgreden derechos constitucionales? Por un lado, bajo la tesis restrictiva, se puede responder que no se divisa un problema interpretativo extraordinario, ya que la ley, al no concederle explícitamente una acción a la persona cuyo progenitor ha fallecido antes que se establezca la filiación, le niega la acción de reclamación, salvo que el reclamante se encuentre en alguno de los supuestos del artículo 206 del Código Civil. "El sentido de los artículos 205 y 206 es claro y no refleja ninguna contradicción o duda que permita desatender su tenor literal a pretexto de consultar su espíritu, siendo los preceptos

${ }^{4}$ C. Suprema, 2 noviembre 2004. L.P. N 31338

5 C. Suprema, 21 septiembre 2006. Rol No 3249-2005; Juzgado de Familia de Valdivia, 25 enero 2007. Rol N C-1505-2006; C. Valdivia, 12 marzo 2007. Rol N 137-2007; C. Suprema, de 18 agosto 2008, con Rol N²893-2008; C. Suprema, 14 octubre 2009. Rol 4783-2009; C. Suprema, 2 agosto 2010. Rol No 3055-2010; C. Santiago, 19 agosto 2010. Rol No 3424-2009; C. Talca, 3 noviembre 2010. Rol N 986-2007; C. Suprema, 11 abril 2011. Rol No 522-2011; C. Suprema, 27 octubre 2011. Rol N 2259-2011; C. Temuco, $1^{\circ}$ marzo 2012. Rol No 405-2011; C. Valparaíso, 14 abril 2008. Rol N 1292-2007; C. San Miguel, 15 septiembre 2010. Rol N 374-2010; C. Temuco, 6 octubre 2010. Rol No 1395-2010; C. Temuco, 20 octubre 2010, Rol Nº 1389-2010. 
Saffie - Inconstitucionalidad del artículo 206 del Código Civil

citados claros en su sentido, contenido y alcances jurídicos. ${ }^{, 6}$ Por otro lado, bajo la tesis amplia, se puede entender que hay un vacío legal respecto de la situación del reclamante de filiación post mortem, que no se encuentra en alguno de los supuestos que establece el artículo 206 del Código Civil.

Ahora bien, ¿cuál es el rol del artículo 206 del Código Civil? A esta pregunta se responde de manera distinta en la tesis restrictiva y en la tesis amplia. En términos generales la tesis restrictiva entiende que el artículo 206 del Código Civil es una excepción a la regla general de la caducidad de la acción de reclamación por la muerte del progenitor y que solo en dichos supuestos se podría entablar la acción de reclamación post mortem. La tesis amplia, por el contrario, fundamenta que la excepción radica en que en los supuestos del artículo 206 del Código Civil existe un plazo para entablar la acción de reclamación, apartándose de la regla general, que permite la posibilidad de entablar la acción de reclamación de filiación sin limitación alguna de tiempo, de forma imprescriptible y sin caducidad alguna. Para refutar la idea de la tesis amplia "(...) se puede decir que si el hijo es póstumo, que es quien requiere una mayor protección, tiene un plazo para demandar a los herederos, parece ilógico que en los demás casos no haya". Más aún, se ha señalado con razón, que "la especialidad adolecería de una razón que la hiciera coherente y legítima como tal. El argumento esgrimido de que en los casos del art. 206 CC habría más dudas de la paternidad no es sustentable, puesto que estamos en el caso de aplicación de pruebas periciales biológicas que disiparían cualquier incertidumbre. No podría la ley ni el legislador haber discriminado en función de supuestos más o menos dudosos de paternidad, cosa que no hace en ninguna otra parte de la regulación de la filiación".

\section{Identidad, igualdad, interés e inconstitucionalidad del artículo 206 del Código Civil}

Para entender el rol del artículo 206 del Código Civil son de gran utilidad los principios inspiradores de la Ley $\mathrm{N}^{\circ}$ 19.585. Entre ellos, el derecho de identidad, que está consagrado en diversos tratados internacionales de derechos humanos, ratificados por el Estado de Chile y que se encuentran actualmente vigentes. Así, la Convención Americana de Derechos Humanos prescribe que toda persona tiene: derecho al reconocimiento de su personalidad jurídica (artículo 3); derecho a que se respete su integridad física, psíquica y moral (artículo 5); derecho al respeto de su honra y al reconocimiento de su dignidad (artículo 11); y derecho a un nombre propio y a los apellidos de sus padres o al de uno de ellos. La ley reglamentará la forma de asegurar este derecho para todos, mediante nombres supuestos si fuere necesario (artículo 18). Por su parte, el Pacto Internacional de Derechos Civiles y Políticos precisa que todo ser humano tiene derecho, en todas

\footnotetext{
${ }^{6}$ GANDARILLAS y MOLINARI (2010).

${ }^{7}$ RAMOS (2009), p. 421.

${ }^{8}$ CORRAL (2009), p. 18.
} 
partes, al reconocimiento de su personalidad jurídica (artículo 16); que todo niño será inscrito inmediatamente después de su nacimiento y deberá tener un nombre ( $\mathrm{N}^{\circ} 2$ del artículo 24). El artículo $7^{\circ}$ de la Convención sobre los Derechos del Niño dispone que: El niño será inscrito inmediatamente después de su nacimiento y tendrá derecho desde que nace a un nombre, a adquirir una nacionalidad y, en la medida de lo posible, a conocer a sus padres y a ser cuidado por ellos. Los Estados Partes velarán por la aplicación de estos derechos de conformidad con su legislación nacional y las obligaciones que hayan contraído en virtud de los instrumentos internacionales pertinentes en esta esfera (...). El artículo $8^{\circ}$ de la misma convención señala que los Estados Partes se comprometen a respetar el derecho del niño a preservar su identidad, incluidos la nacionalidad, el nombre y las relaciones familiares de conformidad con la ley sin injerencias ilícitas. Cuando un niño sea privado ilegalmente de algunos de los elementos de su identidad o de todos ellos, los Estados Partes deberán prestar la asistencia y protección apropiadas con miras a restablecer rápidamente su identidad. En doctrina se ha señalado, que “(...) para que una persona logre desarrollar su personalidad necesita conocer su identidad, es decir, conocer su origen, saber quiénes son sus padres, quiénes constituyen su familia. En síntesis, la identidad es el resultado de la identificación, y para identificarme necesito saber quién soy, investigar mi origen. Para esto, se requiere que el Estado otorgue los medios necesarios para acceder a fuentes veraces de información. Sobre esas bases, la identidad personal comprende: el derecho a la identificación; el derecho al conocimiento de la verdad biológica y a poder investigar la paternidad/maternidad cuando se carezca de ella; el derecho a la formación de la identidad personal y el derecho a la verdad sobre la propia verdad personal".?

La igualdad de toda persona ante la ley está asegurada por el $\mathrm{N}^{\circ} 2$ del artículo 19 de la Constitución. "La idea de igualdad no ignora las diferencias o desigualdades de los seres humanos", ${ }^{10}$ sino que aspira a que las personas que se encuentran en las mismas circunstancias sean tratadas de igual forma y que los que están en situaciones diversas reciban un trato diferente. La desigualdad se justifica cuando hay un motivo razonable para que ella exista.

El interés superior del niño es otro concepto que cobra gran relevancia con la promulgación de la Ley $\mathrm{N}^{\circ} 19.585$, a pesar de no existir en la ley una definición clara al respecto. La primera vez que apareció tal expresión fue, como norma programática, en el Principio $2^{\circ}$ de la Declaración de Derechos del Niño del año 1959, que señala que el niño gozará de una protección especial y dispondrá de oportunidades y servicios, dispensado todo ello por la ley, y de otros medios para que pueda desarrollarse física, mental, moral, espiritual y socialmente en forma saludable y normal, así como en condiciones de libertad y dignidad. Al promulgar leyes con este fin; la consideración fundamental a la que se atenderá será el interés superior del niño. Tres decenas de años después, en el artículo 3 de

9 GÓMEZ DE LA TORRE (2012), p. 60.

${ }^{10}$ SCHMidT y Veloso (2001), p. 31. 
Saffie - Inconstitucionalidad del artículo 206 del Código Civil

la Convención Internacional de los Derechos del Niño, se prescribe, que en todas las medidas concernientes a los niños que tomen las instituciones públicas o privadas de bienestar social, los tribunales, las autoridades administrativas o los órganos legislativos, una consideración primordial a que se atenderá será el interés superior del niño. Con dicho artículo se reconoce explícitamente el carácter de derecho del interés superior del niño, abarcando más que un rol meramente programático. “(...) Es posible afirmar que el interés superior del niño es la plena satisfacción de sus derechos. El contenido del principio son los propios derechos; interés y derechos, en este caso, se identifican. Todo "interés superior" pasa a estar mediado por referirse estrictamente a lo "declarado derecho"; por su parte, solo lo que es considerado derecho puede ser "interés superior". ${ }^{11}$ El principio en cuestión garantiza la vigencia de los demás derechos consagrados, recalcando que estos deben ser satisfechos tanto en su forma como en su contenido.

Es subrayado el interés superior del niño para acentuar el carácter de sujeto de derecho, independiente y desvinculado del que gozan los niños, idea que durante mucho tiempo no fue reconocida. Sin embargo, el significado de este principio no debe ser circunscrito solamente a los "niños", sino que el interés superior protege también a quienes la ley $\mathrm{N}^{\circ} 19.585$ les garantiza algún otro derecho, como la identidad o la igualdad.

El interés tiene gran importancia en este artículo porque "permitiría llenar algunos vacíos o lagunas legales, tanto para la promulgación de nuevas leyes como para tomar decisiones en casos en que no existe norma expresa", "buscando siempre la máxima satisfacción de los derechos que sea posible. Así "en todas las decisiones los derechos de los niños deben primar sobre otros intereses de terceros que no tienen el rango de derechos". ${ }^{13}$ Hay que recordar que "los principios, en el marco de un sistema jurídico basado en el reconocimiento de derechos, puede decirse que son derechos que permiten ejercer otros derechos y resolver conflictos entre derechos igualmente reconocidos". ${ }^{14}$ Por lo que en virtud del interés superior, es decir, de la satisfacción de los derechos, como son el derecho a la identidad y a la igualdad, estos deben prevalecer cuando entran en conflicto con otros derechos.

Ahora bien, no se debe desconocer que habitualmente los elementos históricos y gramatical han sido los de mayor peso en la interpretación de nuestro ordenamiento jurídico, tanto por la jurisprudencia como por la doctrina. Ello ha llevado a un abandono de la búsqueda de los principios inspiradores de cada ley, olvidando la finalidad para la cual fueron dictadas las normas. De ahí, que en la medida que el legislador de la nueva ley ha resaltado a través de todo el texto los principios internacionales que inspiran su espíritu, se puede retomar la importancia de

\footnotetext{
${ }^{11}$ Cillero (1998), p. 78

12 Ibid., p. 82.

13 Ibid., p. 82.

${ }^{14}$ Ibid., p. 77.
} 
los fundamentos teleológicos y el análisis armónico de esta ley y de todo el sistema jurídico chileno.

Pero en segundo lugar sirve al poder judicial como elemento de integración de normas de Derecho de Familia al declarar la derogación tácita o inconstitucionalidad, en su caso, por contradicción de ellos". ${ }^{15}$ Además, “(...) para la aplicación de la ley, debe preferirse siempre aquella interpretación que mejor se avenga con el contenido de la Carta Política Fundamental. Lo anterior porque el sistema jurídico constituye un todo armónico y coherente, cuya validez se desprende a partir de la norma constitucional. En consecuencia, debe presumirse que la norma jurídica de menor jerarquía desarrolla aquello que se expresa en la Carta Magna y en caso alguno contradice su mandato y contenido. Solo de esta manera puede imperar plenamente el principio de supremacía constitucional que informa todo el ordenamiento jurídico". ${ }^{16}$

Teniendo estas consideraciones en cuenta, se puede argumentar que el artículo 206 del Código Civil es inconstitucional, ya que por un lado, el rol que le otorga la tesis restrictiva, no se aviene con los principios inspiradores de la Ley $\mathrm{N}^{\circ}$ 19.585 ni con los derechos constitucionales a la dignidad, a la igualdad y a la identidad. Por otro lado, el papel que le otorga la tesis amplia es ilógico y manifiestamente injusto. “(...) La tesis amplia no anula la inconstitucionalidad implícita del artículo en cuestión, ya que su aplicación en el caso del hijo póstumo o aquél cuyos padres presuntos fallecen dentro de los ciento ochenta días siguientes al parto, resulta con mayor razón injustificada. (...) Cualquiera de las interpretaciones posibles del artículo 206 del C.C. resultan contrarias al principio de igualdad ante la ley". ${ }^{17}$ a raíz de ello, el autor Gonzalo Lepe afirma, que "en consecuencia, haría bien el Tribunal Constitucional en el futuro en declarar inconstitucional el precepto en cuestión". ${ }^{18}$

Se reafirma la inconstitucionalidad del artículo 206 del Código Civil por mandato del inciso segundo del artículo $5^{\circ}$ de la Constitución, que señala que es deber de los órganos del estado respetar y promover los derechos esenciales que emanan de la naturaleza humana, garantizados por la Constitución, así como por los tratados internacionales ratificados por Chile y que se encuentren vigentes. En virtud de dicho deber se dictó la Ley $\mathrm{N}^{\circ} 19.585$, pero la obediencia en esta materia a este precepto no se debe agotar en aquel acto, sino que la promoción de la igualdad y del derecho a la identidad, abarca también el ámbito no legislativo, mediante "la posible derogación tácita de las normas del derecho interno cuando se encuentran en conflicto con los Tratados Internacionales", basándose en que

\footnotetext{
${ }^{15}$ LÓPEZ (2001), p. 208.

16 Rodríguez (2010) (nota 2), p. 123.

${ }^{17}$ LEPE (2010), p. 361.

${ }^{18}$ Ibid.
} 
Saffie - Inconstitucionalidad del artículo 206 del Código Civil

los tratados se incorporan directamente a la Constitución, teniendo un poder jurídico vinculante inmediato". ${ }^{19}$

Otra razón para sustentar que el artículo en cuestión no debe ser aplicado es que en materia de familia el principio del interés exige que se satisfagan, incluso por sobre otros intereses, el derecho a la identidad y a la igualdad. Se ha señalado que "la igualdad se expresa en dos dimensiones: de una parte, debe corregir las desigualdades de hecho, producto de situaciones que derivan de causas naturales o de la realidad social, y de otra, debe eliminar toda diferencia arbitraria o discriminación". ${ }^{20}$ Muchas veces, el aspecto negativo del principio de igualdad es pasado por alto, y se olvida que existe la obligación de ignorar o desconocer mientras no haya fundamento de razonabilidad, necesidad o proporcionalidad los diferentes estatutos a los que se pueden acoger las distintas personas. Ello ayuda a corregir las diferencias de hecho, que no tienen fundamento razonable ni lógico y que derivan finalmente en discriminaciones arbitrarias. Así, aun cuando la ley diferenciará solo entre aquellas personas que se enteran de la muerte de su progenitor después de transcurrido el plazo de tres años desde su muerte, y aquellos que tienen conocimiento de este hecho antes que se cumple el plazo señalado, se estaría atentando contra el derecho de igualdad. A los primeros se les hace imposible ejercer su derecho de identidad, mientras a los segundos se les fija condiciones de acción. A partir de una diferencia de hecho entre ambos grupos (el momento en que se enteran de la existencia de su progenitor), la ley acentuaría la divergencia en la protección del derecho de identidad; sin olvidar que ambos grupos ya están en desventaja respecto de dicha protección, en relación con las personas que se enteran de quien es su padre o madre, en vida de estos.

\section{Posición del Tribunal Constitucional}

$\mathrm{Al}$ analizar los fallos del Tribunal Constitucional se aprecian claramente, a través de los distintos votos, las diferentes formas interpretativas de abordar el problema tratado. $^{21}$ En el voto de minoría de los Ministros señores Marcelo Venegas Palacios e Iván Aróstica Maldonado se aprecia que el silencio de ley significa negar la acción. En cambio, el voto de mayoría en las primeras sentencias entendió que había un conflicto constitucional, ya que se transgredían los derechos constitucionales al aplicar el artículo 206 del Código Civil y/o el artículo $5^{\circ}$ transitorio, incisos tercero y final, de la Ley $\mathrm{N}^{\circ} 19.585$, y que existía una antinomia entre los artículos que dan origen a la discusión, y las normas constitucionales que otorgan el derecho a la igualdad. Llama la atención que la mayoría en las primeras

\footnotetext{
${ }^{19}$ LÓPEZ (2001) (nota 15), p. 51.

${ }^{20}$ GÓMEZ DE LA TORRE (2007), p. 36.

21 TC, 29 septiembre 2009. Rol No 1340-2009; TC, 30 agosto 2011. Rol N 1563-2009; TC, 1 septiembre 2011. Rol N 1656-2009, TC, 1 septiembre 2011. Rol No 1537-2009, TC, 4 septiembre 2012. Rol No 2105-2011; TC, 4 septiembre 2012. Rol N 2035-2011.
} 
sentencias no se haya pronunciado en todos los fallos acerca de la transgresión al derecho a la identidad.

Apartándose del voto de mayoría, el voto de los Ministros señores Enrique Navarro Beltrán y Carlos Carmona Santander argumenta que solo existe problema con los derechos constitucionales, si se sigue la postura restrictiva, es decir, los artículos en cuestión no representan de por sí un problema constitucional, sino solo si se obvia la cuestión interpretativa que originan y la que debe ser resuelta por los jueces de fondo. Con esta postura se insinúa que la tesis restrictiva es inconstitucional, ya que "tomar opción por la tesis restrictiva, como la única posible, para construir la declaración de inconstitucionalidad, implica restringir la utilidad de la inaplicabilidad. En efecto, si se ordena por esta Magistratura dejar de considerar el precepto objetado para la resolución del asunto, quedan subsistentes todas las normas que permiten construir la tesis amplia de la acción de legitimación. Por lo mismo, lo que se estaría haciendo al acoger la inaplicabilidad, es eliminar solo un obstáculo interpretativo para que los jueces lleguen a la misma conclusión si hicieran un esfuerzo de armonización razonable". 22

Otra forma de solucionar este reproche y tratar de conciliar ambas posturas ha sido sustentada en los últimos fallos del Tribunal Constitucional. Se ha entendido que exigir que la acción de filiación contra los herederos del presunto padre se interponga solo cuando este haya fallecido antes del parto o, a más tardar, dentro de los ciento ochenta días siguientes al mismo, es contrario a la igualdad ante la ley. En cambio, exigir que esta se interponga dentro de los tres primeros años de la muerte del supuesto padre o madre o, dentro del primer año, cuando se intente contra los herederos de quienes fallecieron antes de la entrada en vigencia de la Ley $\mathrm{N}^{\circ} 19.585^{23}$ no atentaría contra la Constitución. Así, cualquier persona podría entablar dicha acción, sin importar el momento en que murieron sus progenitores; siempre y cuando la ejerza en el plazo señalado. Se argumenta que existen razones suficientes fundadas en la certeza jurídica,

\footnotetext{
${ }^{22}$ TC, 4 septiembre 2012. Rol N 2035-2011; considerando $13^{\circ}$ del voto en contra de los Ministros señores Enrique Navarro Beltrán y Carlos Carmona Santander.

23 Artículo transitorio $5^{\circ}$ Ley $\mathrm{N}^{\circ}$ 19.585: "Los plazos para impugnar, desconocer o reclamar la filiación, paternidad o maternidad, o para repudiar un reconocimiento o legitimación por subsiguiente matrimonio, que hubieren comenzado a correr conforme a las disposiciones que esta ley deroga o modifica se sujetarán en su duración a aquellas disposiciones, pero la titularidad y la forma en que deben ejercerse esas acciones o derechos se regirá por la presente ley.

Los plazos a que se refiere el inciso anterior que no hubieren comenzado a correr, aunque digan relación con hijos nacidos con anterioridad a la entrada en vigencia de esta ley, se ajustarán a la nueva legislación.

No obstante, no podrá reclamarse la paternidad o maternidad respecto de personas fallecidas con anterioridad a la entrada en vigencia de la presente ley.

Pero podrán interponerse las acciones contempladas en los artículos 206 y 207 del Código Civil dentro del plazo de un año, contado desde la entrada en vigencia de la presente ley, siempre que no haya habido sentencia judicial ejecutoriada que rechace la pretensión de paternidad o maternidad. En este caso, la declaración de paternidad o maternidad producirá efectos patrimoniales a futuro y no podrá perjudicar derechos adquiridos con anterioridad por terceros".
} 
Saffie - Inconstitucionalidad del artículo 206 del Código Civil

impidiendo que estas importantes relaciones de parentesco puedan quedar indefinidas por largo tiempo, evitando también practicar pericias biológicas en restos humanos de antigua data. ${ }^{24}$ Sin embargo, ¿cómo se puede ejercer un derecho cuando por causas ajenas a la propia voluntad se ignora que se goza de este?, ¿cuándo no por propia negligencia, sino que por decisión de un tercero, no se sabe a tiempo la identidad del progenitor?

Tampoco atentarían contra el derecho de identidad el inciso tercero y el inciso final del artículo $5^{\circ}$ transitorio de la Ley $\mathrm{N}^{\circ} 19.585$, ya que solo establecerían condiciones para ejercer el derecho legal a reclamar la filiación; entendiendo que su imprescriptibilidad tiene rango legal, por lo que otra ley puede establecer condiciones para su ejercicio, sin atentar por ello contra la Constitución. ${ }^{25}$ "El artículo $5^{\circ}$ transitorio de la Ley $\mathrm{N}^{\circ} 19.585$ diseña un sistema especial y único para regular las situaciones generadas con anterioridad a su entrada en vigencia"; ${ }^{26}$ permitiendo un reclamo judicial sujeto a un límite temporal, sin transgredir por ello la Constitución. "El artículo $5^{\circ}$ transitorio de la Ley $\mathrm{N}^{\circ} 19.585$ es claramente favorable. Salvo las situaciones de los artículos 206 y 207 del Código Civil, todos los demás hijos no pueden demandar de reconocimiento de paternidad o maternidad a los padres muertos". ${ }^{27}$ Sorprende que al aceptar la plena constitucionalidad del artículo $5^{\circ}$ transitorio de la Ley $\mathrm{N}^{\circ}$ 19.585 se está avalando también la constitucionalidad del artículo 206 del Código Civil, ya que para que se aplique el inciso final del artículo $5^{\circ}$ transitorio de la Ley $\mathrm{N}^{\circ} 19.585$ se debe dar alguna de las hipótesis del artículo 206 del Código Civil.

\section{Supuesta inestabilidad en la adquisición del dominio por sucesión por causa de muerte}

En doctrina se ha manifestado que si la regla general fuese el artículo 317 del Código Civil, “(...) toda asignación hereditaria debe considerarse condicional, ya que estaría sujeta al hecho futuro e incierto de que el reconocimiento de un descendiente -incluso años después de la muerte de sus padres- haría perder todo o parte del dominio adquirido". ${ }^{28}$ Según esta idea, estarían inestables los derechos hereditarios de la sucesión, mientras no se cumple el plazo necesario para que los adquiera por prescripción. Además se ha sugerido que para resguardar la certeza jurídica y evitar alteraciones posteriores e imprevisibles, que puedan atentar contra la paz familiar, se debe consignar que “(...) el reconocimiento que se obtiene por sentencia judicial en juicio iniciado después del

\footnotetext{
${ }^{24}$ Ver TC, 4 septiembre 2012. Rol N 2035-2011; considerando $8^{\circ}$.

${ }^{25}$ Ver TC, 4 septiembre 2012. Rol N² 2035-2011; considerando $6^{\circ}$ de la prevención efectuada por los Ministros señores Enrique Navarro Beltrán y Carlos Carmona Santander.

26 TC, 4 septiembre 2012. Rol N 2035-2011; considerando $5^{\circ}$ de la prevención efectuada por los Ministros señores Enrique Navarro Beltrán y Carlos Carmona Santander.

27 TC, 4 septiembre 2012. Rol N 2035-2011; considerando $7^{\circ}$ de la prevención efectuada por los Ministros señores Enrique Navarro Beltrán y Carlos Carmona Santander.

${ }^{28}$ Rodríguez (2010) (nota 2), p. 135.
} 
fallecimiento de presunto padre o madre, no tendrá efectos patrimoniales ni alterará la adquisición de las asignaciones diferidas a la muerte del causante". ${ }^{29}$

Sin embargo, el riesgo señalado no es significativo. El mismo autor señala que "el único paliativo que ofrece la ley, en este caso, es lo previsto en el artículo 221 del Código Civil, pudiendo los ascendientes alegar haber adquirido la herencia de "buena fe"." 30 En ese sentido si quienes creían ser los herederos vendieron la herencia o parte de esta a un tercero, en virtud del artículo señalado, este tendrá resguardado su derecho. Además, los mismos herederos, si son putativos, tienen la posibilidad de adquirir la herencia por prescripción ordinaria de cinco años o, de lo contrario, en diez años. Hay normas de prescripción aptas para resguardar la certeza jurídica. Esta idea es respaldada por el autor José Francisco Sepúlveda, al señalar que "la estabilidad de la sucesión hereditaria encuentra protección suficiente en las normas sobre prescripción. El que ha sido declarado hijo tendrá siempre la acción de petición de herencia, salvo que haya transcurrido más de 10 años desde la muerte del causante, caso en el cual, por una parte, su acción habrá expirado, y por la otra, habrá quien haya adquirido esos bienes. Diez años son seguridad jurídica suficiente". ${ }^{31}$

\section{Comentario final}

En un principio, la jurisprudencia acogía la tesis restrictiva, luego de un cambio en la perspectiva se tendió a la tesis amplia.

La tesis restrictiva entiende que el silencio de ley niega la acción de reclamación de filiación contra los herederos del supuesto progenitor difunto, excepto se dé alguna de las hipótesis del artículo 206 del Código Civil. En cambio, la tesis amplia argumenta que existe un vacío legal, cuya solución es otorgar la acción sin limitación de tiempo, salvo a quienes estén en alguno de los casos del artículo 206 del Código Civil; ellos tendrían plazo para entablarla. Sin embargo, ninguna de las posiciones soluciona de manera satisfactoria el problema.

El artículo 206 del Código Civil no debería tener aplicación en caso alguno, porque atenta contra los derechos constitucionales de dignidad, de identidad, de igualdad, al principio de supremacía constitucional y es contrario a los principios inspiradores de la Ley $\mathrm{N}^{\circ} 19.585$.

El interés superior, en el problema en cuestión, dicta la satisfacción del derecho a la identidad y a la igualdad, principios que deben prevalecer cuando hay conflicto con otros derechos.

\footnotetext{
${ }^{29}$ Ibid., p. 137.

${ }^{30}$ Ibid., p. 136.

${ }^{31}$ Sepúlveda (2010a), p. 97.
} 
Saffie - Inconstitucionalidad del artículo 206 del Código Civil

En virtud del artículo $5^{\circ}$ de la Constitución se puede defender la derogación tácita del artículo 206 del Código Civil, ya que aquel prescribe la promoción de la igualdad y del derecho a la identidad en la aplicación de la Ley $\mathrm{N}^{\circ} 19.585$.

Los derechos patrimoniales de los herederos y la paz familiar no están en peligro al no aplicarse el artículo 206 del Código Civil, porque las actuales normas de prescripción son aptas para resguardar la certeza jurídica.

En los fallos del Tribunal Constitucional se aprecian claramente las distintas posturas que se han adoptado al abordar el tema.

Finalmente, cabe señalar que es de suma importancia que este tema sea zanjado de forma definitiva, ya que al no existir certeza del rol del artículo $206 \mathrm{del}$ Código Civil y del inciso tercero y del inciso final del artículo $5^{\circ}$ transitorio de la Ley $\mathrm{N}^{\circ} 19.585$, surge el peligro que el estado civil de una persona dependa de la tendencia jurídica que sustente el tribunal que conozca la causa. 


\section{BIBLIOGRAFÍA}

* ABELIUK, René (2000): La filiación y sus efectos (Editorial Jurídica de Chile, Santiago de Chile).

* Cillero, Miguel (1998): "El interés superior del niño en el marco de la Convención Internacional sobre los Derechos del Niño", en Méndez, Emilio y Beloff, Mary, Infancia, Ley y Democracia en América Latina (Editorial Temis-Ediciones Depalma, Santa Fe de Bogotá-Buenos Aires).

* CORRAL, Hernán (1999): "Determinación de la filiación y acciones de estado en la reforma ley $\mathrm{N}^{\circ}$ 19.895”, en Revista de la Universidad Católica de Valparaíso (20) (Universidad Católica de Valparaíso).

(2009): “¿Puede interponerse la acción de reclamación de filiación en contra de los herederos del supuesto padre fallecido?”, en Gaceta Jurídica (347) (Legal Publishing Chile, Santiago).

(2009) "¿Subsisten discriminaciones en el actual régimen legal chileno de filiación?, en Discriminación en la filiación, II Congreso de Estudiantes de Derecho Civil (Facultad de Derecho de la Universidad de Chile, Santiago de Chile).

* Elorriaga, Fabián (2005): Derecho Sucesorio (Lexis Nexis, Santiago de Chile).

* EVANS, Enrique (1999): Los Derechos Constitucionales, tomo II (Editorial Jurídica de Chile, Santiago).

* GANDARILLAS, Cristián y MOLINARI, Aldo (2010): "Legitimidad pasiva de la acción de reclamación de la filiación no matrimonial y caducidad de la acción de impugnación de la filiación determinada antes de la Ley $\mathrm{N}^{\circ}$ 19.585: necesidad de uniformar criterios”, en Departamento de Derecho Privado, Universidad de Concepción (Chile), Estudios de Derecho V (LegalPublishing, Santiago de Chile).

* GÓMEZ DE LA TORRE, Maricruz (2007): El sistema filiativo chileno (Editorial Jurídica de Chile, Santiago de Chile).

(2012) "El derecho de la identidad y la filiación", en: XVII Congresos Internacionales de Derecho Familiar Disertaciones y Ponencias (La Ley Abeledo Perrot, Buenos Aires).

* LARROUCAU, Jorge (2012): "Padres e hijos, La acción para reclamar la filiación cuando el supuesto padre ha fallecido", en Jornadas chileno-uruguayas de Derecho Civil "Gonzalo Figueroa Yánez" (1 ${ }^{\circ}$, Facultad de Derecho Universidad de Chile).

* LEPE, Gonzalo (2010): "Inaplicabilidad por inconstitucionalidad del artículo 206 del Código Civil (Tribunal Constitucional)", Revista Derecho 23 (1) (Universidad Austral de Chile, Facultad de Ciencias Jurídicas y Sociales).

* LÓPEZ, Gissella (2001): Nuevo estatuto de filiación y derechos esenciales (Editorial Jurídica ConoSur Ltda., Santiago de Chile).

* PIZARro, Carlos (1999): "Algunas consideraciones en torno a la determinación y acciones de filiación en la ley 19.585", Ius et Praxis 5 (002) (Universidad de Talca, Facultad de Ciencias Jurídicas y Sociales).

* RODRÍGUEZ, Pablo (2010): “Comentario de la sentencia del Tribunal Constitucional de 29 de septiembre de 2009, mediante la cual se declara inaplicable el artículo 206 del Código Civil" en Fermandois, Arturo y Delaveau, Rodrigo (eds.), Sentencias destacadas 2009: una mirada desde la perspectiva de las politicas públicas: Corte Suprema, Cortes de Apelaciones, Tribunal Constitucional, Tribunal de Defensa de la Libre Competencia (Libertad y Desarrollo, Santiago de Chile).

* RAMOS, René (2009): Derecho de Familia, Tomo II, $\sigma^{a}$ edición actualizada (Editorial Jurídica de Chile, Santiago de Chile).

(2003) "Legitimación pasiva de los herederos en un juicio de reclamación de filiación", Revista de Derecho Universidad de Concepción (214) (Universidad de Concepción, Concepción). 
Saffie - Inconstitucionalidad del artículo 206 del Código Civil

* SÁNCHEZ, Verónica (2009): Procedencia de la acción de reclamación de paternidad o maternidad cuando el presunto padre o madre ha fallecido: un estudio doctrinario y jurisprudencial, Tesis Magíster en Derecho (Escuela de Graduados, Facultad de Derecho, Universidad de Chile, Santiago).

* SCHMIDT, Claudia y VELOSO, Paulina (2001): La filiación en el nuevo derecho de familia (Cono Sur LexisNexis, Santiago de Chile).

* SEPúlvedA, José Francisco (2010a): "La acción de reclamación de la filiación intentada contra los herederos del supuesto padre o madre fallecido", Revista Chilena de Derecho de Familia (2) (Abeledo Perrot Legal Publishing, Santiago).

(2010b) "Filiación, Discriminación en acciones de filiación: inaplicabilidad por inconstitucionalidad del artículo 206 del Código Civil", Revista Chilena de Derecho de Familia (2) (Abeledo Perrot Legal Publishing, Santiago).

(2010c) "Filiación, Prescripción de la acción de reclamación de la filiación", Revista Chilena de Derecho de Familia (3) (Abeledo Perrot Legal Publishing, Santiago).

* TURNER, Susan (2007): "Transmisibilidad y disponibilidad de la acción de reclamación de filiación, Sentencia sobre el alcance de la legitimación pasiva de la acción de reclamación intentada por el hijo (Juzgado de Familia de Valdivia, Corte de Apelaciones de Valdivia)", Revista Derecho 20 (2) (Universidad Austral de Chile, Facultad de Ciencias Jurídicas y Sociales, Valdivia).

\section{Textos constitucionales y legales:}

* Resolución No 217 de la Asamblea General de las Naciones Unidas de 10 de diciembre de 1948. Declaración Universal de Derechos Humanos.

* Resolución No 1386 (XIV) de la Asamblea General de las Naciones Unidas de 20 de noviembre de 1959. Declaración Universal de Derechos del Niño.

- Decreto No 326, del Ministerio de Relaciones Exteriores. Diario Oficial de 27 de mayo de 1989. Pacto Internacional de Derechos Económicos, Sociales y Culturales.

* Decreto No 778, del Ministerio de Relaciones Exteriores. Diario Oficial de 29 de abril de 1989. Pacto Internacional de Derechos Civiles y Políticos.

- Decreto $\mathrm{N}^{\circ}$ 789, Diario Oficial de 9 de diciembre de 1989. Convención Sobre Eliminación de Todas las Formas de Discriminación Contra la Mujer.

* Decreto No 830, Diario Oficial N 33.779 de 27 de septiembre de 1990. Convención Sobre los Derechos del Niño.

* Decreto No 873, del Ministerio de Relaciones Exteriores. Diario Oficial No 33.860 de 5 de enero de 1991. Convención Americana sobre Derechos Humanos denominada Pacto de San José de Costa Rica.

* Ley No 19.585. Reforma al Código Civil Chileno, Diario Oficial N 36.197 de 26 de octubre de 1998.

* Ley N ${ }^{\circ}$ 19.969. Crea los Tribunales de Familia. Diario Oficial 30 de agosto de 2004.

* Ley $\mathrm{N}^{\circ}$ 20.030. Modifica el Código Civil, en lo relativo a la exigencia de presentación de antecedentes para dar curso a la demanda de reclamación de maternidad o paternidad, y a la valoración de los medios de prueba sobre el particular. Diario Oficial 5 de julio de 2005.

* Decreto Supremo No 100, de 22 de septiembre de 2005, del Ministerio Secretaría General de la Presidencia. Constitución Política de la República de Chile. $11^{\circ}$ edición oficial.

* Decreto No 838, de 20 de octubre de 2004, del Ministerio de Justicia. Editorial Jurídica de Chile. 2005. Código Civil. $16^{a}$ edición oficial. 